IKER

FIDALGO ALDAY
Investigador independiente ikerfidalgo@gmail.com

\title{
El archivo de la "Fundación Rodríguez". Análisis, potencia y gestión del legado
}


THE ARCHIVE OF THE “FUNDACIÓN RODRÍGUEZ”. ANALYSIS, POWER AND MANAGEMENT OF THE LEGACY

\section{ABSTRACT}

This article starts from a concrete case study that is the research around the archive of the artistic collective "Fundación Rodríguez" (Vitoria-Gasteiz, 1994-2012). The research process will be marked by all that is involved in dealing with an archive composed of digital content and formats on the verge of obsolescence, as well as the difficulties of preserving and maintaining them. Starting from this, the practice of "Fundación Rodríguez" and the role played by the concept of archive in several of the phases of its artistic production will be contextualized. To do so, we will analyze its position from the perspective of collective work, the dissolution of the role of the artist and the dematerialization of the artistic work as the three main fronts from which its production is built. With all this, we will be able to evaluate from the present time the validity and relevance of his legacy as well as its power in the artistic context to which it belongs.

\section{Keywords}

Archive, digital, collective, dematerialization, memory.

\section{RESUMEN}

El presente artículo parte de un caso de estudio concreto que es la investigación en torno al archivo del colectivo artístico "Fundación Rodríguez" (Vitoria-Gasteiz, 1994-2012). El proceso de investigación estará marcado por todo lo que conlleva enfrentarse a un archivo compuesto por contenido digital y con formatos a punto de la obsolescencia, así como las dificultades para su conservación y mantenimiento. Partiendo de esto, se contextualizará la práctica de "Fundación Rodríguez" y el papel que juega el concepto de archivo en varias de las fases de su producción artística. Para ello analizaremos su posición desde el trabajo colectivo, la disolución del rol del artista y la desmaterialización de la obra artística como los tres frentes principales desde los que se erige su producción. Con todo, podremos valorar desde la actualidad la vigencia y relevancia de su legado, así como la potencia del mismo en el contexto artístico al que pertenece.

\section{Palabras clave}

Archivo, digital, colectivo, desmaterialización, memoria. 


\section{INTRODUCCIÓN}

En el año 2012 el colectivo artístico formado por Natxo Rodríguez y Arturo/fito Rodríguez dio por finalizada una actividad que se remonta a 1994 y que los sitúa como uno de los colectivos más reseñables de su momento. Su práctica entre lo performático, el activismo cultural y la creación de formatos híbridos de comisariado y producción artística en el contexto del arte digital y la exploración de nuevos medios, los hace artífices de un legado que a día de hoy merece ser tenido en cuenta. Sus obras están plagadas de humor, de métodos provenientes de la cultura do it yourself y exploración sobre los modos colectivos en donde la cuestión de archivo se ha desarrollado desde diferentes frentes.

Muchos de sus proyectos han intervenido directamente en las maneras de creación y gestión cultural, proponiendo una figura que va más allá del artista/comisario y se enfrenta a la búsqueda de otros espacios para la creación conjunta. Situándolos en la segunda etapa de los años 90 y en la primera década de los años 2000 , la creación web asumió un protagonismo ineludible, no tanto como una producción basada en el net.art a pesar de ser piezas y proyectos "que utilizan simultáneamente el potencial de la Red como espacio de exposición y como medio de creación" (Baigorri y Cilleruelo, 2006, p. 7), si no que exploraron ese terreno casi como la reivindicación de una independencia de toda la impostura del mundo del arte, renunciando a lo mercantil del producto, la espectacularidad del nombre propio y los renqueantes circuitos institucionales. Es por eso que muchos de sus trabajos tienen aún hoy una huella presente en internet, páginas web que permanecen activas y que un servidor sigue manteniendo en marcha, CD-ROMS o DVDs que pueden encontrarse descargables, así como documentación en forma de imágenes, blogs o textos online.

En muchas ocasiones la Fundación Rodríguez es a la vez autora, productora, institución, empresa y gestora de un contenido poco controlable y de carácter expandido, con reminiscencias fanzineras pero con un alto grado de compromiso con el contexto y la creación de espacios para la creación de red y el compromiso político.

Tras el cese de su actividad, la totalidad de su producción fue cedida en depósito al Centro-Museo Vasco de Arte Contemporáneo ARTIUM de Vitoria-Gasteiz para su catalogación y conservación. El archivo se compone principalmente de un disco duro plagado de carpetas rigurosamente ordenadas por fecha, dentro de cada cual se encuentra documentación sobre los diferentes proyectos llevados a cabo por el colectivo. Se amontonan cientos de archivos en diferentes formatos, fotografías, documentación, correos electrónicos, memorias de subvenciones o pruebas de diseño para camisetas, folletos y pósteres. El archivo entregado también cuenta con una parte física en el que podemos encontrar originales de publicaciones y elementos utilizados para acciones y performances.

Este artículo desarrollará simultáneamente dos capas que son a su vez paralelas y complementarias respecto a la temática que plantea el volumen de la publicación. Por un lado, analizará la producción del colectivo y la manera en que el archivo ha estado presente en el desarrollo de su práctica siendo en ocasiones elemento importante de sus piezas y espacio de reflexión crítica. Por otro, la propia experiencia que ha supuesto desgranar todo el material compuesto principalmente de elementos en vía de quedarse obsoletos para su visionado y todas las consecuencias a las que nos enfrentamos cuando las prácticas artísticas abandonan la materialidad exclusivamente física y se desatan nuevos diálogos entre lo tecnológico y los 
espacios de conservación, almacenamiento y catalogación.

Esta investigación ha sido posible gracias a la financiación del Departamento de Euskera, Cultura y Deporte de la Diputación Foral de Álava quien propuso mediante convocatoria pública la convocatoria de becas en residencia para investigación en el Centro-Museo de Arte Contemporáneo ARTIUm y el Museo Bellas Artes de Álava durante los ejercicios del $2017^{1}$ y el $2018^{2}$.

\subsection{Situar la práctica "Rodriguista"}

Como todo movimiento radical que se precie, Fundación Rodríguez tuvo también su manifiesto fundacional. Sin ser uno de sus textos más habituales, aún puede encontrarse online en una de las webs que el colectivo tiene activas. La radicalidad de la Fundación reside en varias acepciones de la palabra. Por un lado, por la clara intención de hacer frente maneras de hacer en el contexto del arte a las que se oponen frontalmente con la intención de cambio. Por otro, porque apuntan a la raíz de la cuestión hacia los lugares donde surgen las oportunidades de crear estos otros modos de hacer y reivindicando el contexto local tanto de Vitoria-Gasteiz como de Euskal Herria. Territorio marcado por una herencia artística que se ha basado (y aún se basa en muchas ocasiones) en la influencia de la escultura vasca (y sus posteriores etapas) y las tendencias formales que se han convertido en una seña de identidad sobre todo de la muga hacia fuera. Pero también cargado de una potente estela de movimientos de autogestión y de estructuras afianzadas en los movimientos sociales y espacios alternativos de gran arraigo comunitario.

El "Rodriguismo", manera a la que ellos mismos se refieren en ocasiones a su propia práctica, bebe entonces de experiencias colectivas previas. Desde su primera etapa (1994-1998) formando junto con otro colectivo (el I.M.A=International Mola Art) parte de la S.E.A.C (Selección Euskadi de Arte de Concepto). Este ecléctico sumatorio daba como resultado un colectivo de cuatro miembros que a su vez estaba formado por dos colectivos de dos. Esta intencionada mistura de nombres provoca una autoría cuestionada desde "el higiénico ejercicio de disolución de la autoría" (Francisco Javier San Martín, 2016, p. 13) donde la representación de la producción no recae sobre una ensalzada figura de creador único. En este momento su trayectoria colectiva tiene que ver de una forma mucho más cercana a los grupos artísticos de herencia situacionista, así como de los métodos Punk y la distribución autogestionada (esta parte de forma especialmente visible en el trabajo de la S.E.A.C).

Si bien durante su primera etapa como parte de S.E.A.C la colectividad se establece en base a un trabajo que no trasciende del estrato de lo artístico, su consolidación posterior supera el rol de artistas para convertirse en agentes culturales multitarea cuya labor se expande hacia la gestión cultural, la labor comisarial, el trabajo colaborativo con instituciones y la creación de formatos de producción y difusión afines a su propia temporalidad. En este sentido Fundación Rodríguez parece acercarse a una lógica casi empresarial (constituidos legalmente como Asociación Cultural de Artistas Rodríguez) en la que son capaces de ofrecer diferentes servicios, proyectos y propuestas susceptibles de funcionar de diferentes maneras.

Partimos de un contexto, segunda mitad de los años 90, en el que la renovación de Bilbao con la entrada del Museo Guggenheim (1997) marcaría el devenir de la industria artística y cultural del territorio. Mientras espacios como Arteleku (muy presentes en la producción de la 
Fundación) permitían lugares para la experimentación y la producción más allá de la facultad de Bellas Artes del Campus de Leioa en Bilbao, las políticas culturales avanzarían hacia una manera de funcionar que ha sido el terreno de crecimiento de muchos proyectos que aún hoy han sobrevivido, mutado o simplemente desaparecido víctimas de lógicas de subvención pública ahogantes e insostenibles para el tejido. A su vez en los años anteriores, 80-90 cuestiones como el antimilitarismo o la okupación aparecen siempre impregnados de la autogestión y la creación de circuitos alternativos de difusión cultural. La Fundación Rodríguez desempeña un papel protagonista entre ambos mundos promoviendo un acceso a las políticas por parte de los agentes protagonistas y abogando por una reivindicación de una figura "multitarea" capaz de ir más allá de la creación de obras y abogar por la configuración de espacios de reflexión política y formatos que desafíen la cultura más anodina.

\begin{abstract}
Al final de los 90, la situación cultural que vivimos sigue siendo presidida por la rentabilidad comercial, mediática y política en última instancia. El liberalismo radical-cultural se ha establecido definitivamente en el horizonte de los macroproyectos museísticos y culturales, y Fundación Rodríguez toma cartas en el asunto en una suerte de filantropismo suicida, huida hacia delante, voluntarismo, responsabilidad y conciencia cósmica. (...) No trabajamos la idea del artista-gestor, sino que asumimos responsabilidades desde nuestros presupuestos artísticos, que nos permiten de igual modo organizar eventos que componer performances; No buscamos nuestra identificación con asociación cultural o de gestión, sino que disfrutamos extendiendo nuestro quehacer hasta nuevos territorios en los que poder conocer gente nueva y nuevas actitudes (...). Fundación Rodríguez no escribiría un manifiesto, pero no se avergüenza de tener web-site. (Fundación Rodríguez, s.f)
\end{abstract}

En el extracto de su manifiesto se advierte claramente como Fundación Rodríguez asume un compromiso con el desarrollo del ámbito artístico de su contexto y presenta las tres líneas principales en las que se basa la investigación que nos ocupa, así como el posterior análisis de su legado. Por un lado, la cuestión colectiva como reivindicación de creación conjunta, modos de hacer y estructura intocable de su labor. Por otro, la disolución de los roles, conformando una figura híbrida capaz de adaptarse a cada situación sin pretender ocupar un espacio de legitimación como artistas, gestores, investigadores o comisarios, pero sin renunciar a ninguna de las labores que el devenir de sus proyectos les pueda conceder e incluso practicando el hackeo de esas posiciones. Por último, la alineación y reivindicación de unos modos de creación y distribución identificados con la desmaterialización de la obra artística, renunciando al objeto en favor del soporte (Dvd, CD-Rom) y la cultura Copyleft, tan habitual en otros ámbitos creativos, pero tan escasa en el ámbito artístico.

A finales de los 90 o principios de los años 2000, la creación de proyectos cuyo soporte es una página web o un soporte digital respondía a una lógica para la lectura y ejecución de su contenido que apenas 20 años después, ha variado completamente. Además, muchos de los productos finales creados por el colectivo seguían un planteamiento de diseño similar al proceso de una publicación con libreto, textos y packaging ad hoc por lo que no se trataban únicamente de herramientas para el almacenaje.

Actualmente los dispositivos para la reproducción de DVD están prácticamente en desuso, los ordenadores portátiles no cuentan con bandeja para su lectura y ni que decir tiene el arduo camino que puede suponer intentarlo con un CD-Rom. En este momento, aquellos proyectos que 
propiciaban la desmaterialización de la obra artística para convertirla en un elemento portátil, barato, asequible y que propusiera otras formas de difundir, almacenar y poseer, parece que han dado el giro completo para volver al punto de partida, siendo ahora elementos cuya frágil conservación depende del rapidísimo avance de la tecnología actual y de la posibilidad de que un disco grabado hace 15 años simplemente haya dejado de funcionar.

Afortunadamente la producción de Fundación Rodríguez en proyectos como "Tester "o "Arte y Electricidad", que explicaremos más adelante, no radica solo en el empaquetado final. Estamos ante trabajos procesuales constituidos a base de relaciones y de esquemas de trabajo descentralizados y horizontales que consiguieron conectar varios contextos, ciudades y artistas. Sin embargo, desde un punto de vista de conservación museística, esa memoria queda relegada a una suerte de tangibilidad catalogable pero inaccesible. Aquel legado inmaterial adquiere ahora una nueva materialidad a medio camino entre la conservación de un volumen como un libro o un vinilo y la necesidad de extraer del formato en vías de obsolescencia el relato de la experiencia como la verdadera potencia del trabajo artístico y político del colectivo. Es en este momento, como en otros ámbitos del arte contemporáneo, donde entra la producción de investigación historiográfica, teórica e incluso comisarial, para articular nuevas maneras de adaptar el contenido a las formas de lectura actuales.

De todas maneras, hemos de tener en cuenta que desde el principio Fundación Rodríguez ha tenido en su propia genética una relación con la cultura digital. "Aglutinantes y disolventes" o "En el antiguo frontón han puesto un cibercafé" son proyectos del año 1996 y 1999 respectivamente en cuyas líneas temáticas se encontraban reflexiones en torno al vídeo digital e incluso, como en el caso del segundo, contaron con una página web que no era solo un mero espacio informativo, sino que podríamos entenderlo como una parte de la propia filosofía del proyecto. Al igual que durante el periplo de la S.E.A.C gran parte de sus actividades fueron performances o acciones que cuentan a día de hoy con escasa documentación, es fácil pensar que en el propio planteamiento de cada proyecto la cuestión de la durabilidad asociada a internet era una problemática que, o bien, no pudiera existir, o que simplemente no se pensara como una documentación a posteriori pues lo importante era lo que sucedía en ese momento y las sinergias que podría suscitar. Una de las características de nuestra convivencia con internet es esa sensación de eternidad con la que de manera inconsciente nos familiarizamos. Un espacio plagado de información y recursos que pareciera que nunca se fuera a apagar y que se alimenta de contenido. A pesar de aquellas advertencias de Virilio cuando nos hablaba de "el accidente general" (Virilio, 1997, p. 48), respecto a los problemas de la conectividad global y la interconexión mundial a través de internet nuestra cotidianeidad sigue siendo un constante visionado de información condenada a desaparecer en donde la calidad, la procedencia o la condición poco importa respecto a su condición de instantánea. La "Imagen pobre" (Hito Steyerl, 2014, p. 32) que ya ha perdido su lugar de pertenencia y circula sin ningún tipo de arraigo nos rodea y nos condiciona como público. Por todo eso puede que en un golpe de realidad quizás aquellos restos materiales que han quedado depositados en un museo a fin de cuentas no sean tan importantes y la verdadera cuestión a rescatar del archivo sea toda esa herencia intangible que aportó a su propio contexto. 
Tras desarrollar el punto anterior en el que hemos ubicado la génesis de la práctica de la Fundación Rodríguez, así como esbozado las características básicas de su metodología de trabajo, conviene ahondar en el proceso de investigación que parte directamente del desglose y del archivo digital depositado en el museo vasco.

El archivo está compuesto por diferentes tipos de archivo que responden a la manera de trabajo del colectivo. Gran parte de este es mera documentación. Fotografías de eventos, vídeos de registros de performances o conferencias, así como textos o publicaciones. Por otro lado, existe una gran cantidad de material que se refiere al trabajo interno del propio grupo. Actas de reunión, bocetos de presupuestos, emails enviados o memorias justificativas de subvenciones o como cierre de un proyecto. Por último, una reseñable cantidad de capturas de páginas web o archivos ejecutables desde el navegador que nos permiten acceder a espacios que ya no están más disponibles en la red. Por supuesto, las publicaciones realizadas en formato DVD y CD Rom que aún pueden verse desde dispositivos adecuados para ello. Ese carácter multitarea del colectivo se refleja entonces en un legado ecléctico en el que, además, dentro del tremendo trabajo de ordenación ya realizado para poder depositarlo en la institución museística, existe una clara intencionalidad de poner al mismo nivel diferentes proyectos. Aquellos terminados y perfectamente encuadrados en un tipo de producción concreta junto con otros más cercanos a conversaciones, reflexiones o lugares de intimidad organizativa de puertas adentro que los propios autores han convenido debe ser tenida en cuenta para el entendimiento de todo lo que el contenido supone.

Por todo esto, la manera de estructurar la investigación no fue (y no debía ser) la de catalogar contenido por tipo de documento o fecha hasta obtener un listado de fichas sobre cada elemento. Por supuesto se realizó una labor de visionado de todas y cada una de carpetas y subcarpetas que lo componían para poder crear un índice desde el que trabajar para navegar entre tanto tipo de documentación sin jerarquizar. Finalmente, se decidió que el objetivo final era la creación de un texto teórico que pudiera analizar el legado de Fundación Rodríguez desde la panorámica que proporciona la distancia temporal y la posibilidad de valorar desde el ahora como única manera de construir un relato que pudiera aglutinar tanta información y dar una opción de trasmisión de esa memoria. A fin de cuentas, un archivo ilegible pierde la función de su propia conservación si no es para poder ser leído a posteriori.

Cabe destacar que existían muchos espacios en blanco en los que el rompecabezas necesitaba ser completado para entender la mecánica de algunos de sus proyectos, así como algún tipo de suceso que podía aparecer mencionado en un documento que recogía el acta de una reunión. Todo esto que pudiera parecer anodino o incluso ruidoso para la búsqueda de sentido era sin embargo material imprescindible para ahondar en la capa más prolífica del colectivo, aquella que desvelaba su trato con instituciones o proyectos. Estaban como decimos, al mismo nivel este tipo de situaciones que el registro de una performance o el texto de una charla, lo que hacía que las posibilidades se expandieran en cada nueva carpeta.

Para poder dar buena cuenta de todo esto, se buscaron algunas de las personas que fueron cómplices en algún momento de la trayectoria y que desde su valoración personal ayudaron a hilvanar gran parte del relato. Si bien las conversaciones no fueron transcritas como tal, la investigación cuenta con la visión de nombres como Jorge Luis Marzo, Santiago Eraso, Marcelo 
Expósito o Txelu Balboa, quienes vivieron parte de la producción rodriguista desde su propio lugar y ayudaron en la comprensión general del material.

Sobre esta especificidad del archivo Fundación Rodríguez, conviene utilizar como ejemplo un caso concreto que forma parte de la documentación. En el año 2007, la Fundación recibe una ayuda concedida por el Gobierno Vasco para el desarrollo del proyecto "Condensadores" dentro de la "Convocatoria de subvenciones para el fomento y desarrollo de actividades en el área de Artes Plásticas y Visuales". En una carta con fecha de entrada el 21 de septiembre del 2007, exponen una serie de motivos por los cuales el sistema de subvenciones públicas condenaba a los proyectos artísticos a nadar en una consecución de indefiniciones y justificaciones previas a la recepción de la ayuda económica que no hacía sino incrementar el estado de indefensión y precariedad de los solicitantes. En el propio texto, se observa una decadencia de las instituciones artísticas del territorio, que, desde el propio punto de vista profesional de la Fundación, no hace más que incidir en un bucle infinito del que no se puede salir y del que es necesaria una revisión. Entre otras cosas, aluden a otra comunicación realizada vía carta en el año 2000 en el que la imposición de los plazos de justificación imposibilitan la salubridad de la gestión económica del proyecto, así como su participación en el año 2005 en el Plan Vasco de Cultura junto a Santiago Eraso, Franck Larcade (fundador de consonni) y Lucía Onzain (Gobierno Vasco, Dpto. de Cultura, 2004) en el que realizaron un extenso trabajo de análisis de la situación y en la que advertían de la necesidad precisamente de replantear dicha convocatoria.

La carta es una auténtica declaración de principios en la que advierten de la dificultad de asumir, por un lado, que si bien esa convocatoria es una de las entradas económicas más necesarias para el arte del contexto es inviable lidiar con los sinsentidos de la gestión que acaba sepultando bajo espacios de precariedad cualquier intento de proyecto. Con un espíritu claro de aludir a los organismos responsables y de reclamar un espacio de decisión, consulta y debate con los profesionales de la cultura, la misiva es a la vez una carta de renuncia a dicha subvención. El texto que será publicado en algunos de los canales que la Fundación utilizaba como espacios de participación y discusión sobre la situación del arte en Euskal Herria, acabó siendo público generando líneas de debate y discusiones en foros con temáticas que aún hoy permanecen totalmente actuales.

El tono de la investigación que describíamos en los párrafos anteriores cobra ahora todo el sentido. La comunicación del colectivo con los organismos públicos, así como todo lo que sucede tras la publicación de la renuncia, está al mismo nivel de relevancia que los proyectos artísticos que realizaron y que se conservan documentados. Este suceso que rescata una cuestión mucho más actitudinal que artística permite que el relato de Fundación Rodríguez sea entendido con todos sus matices aportando unas capas de complejidad a la narración que necesitan ser desarrolladas. El texto dirigido al Gobierno Vasco es a la vez un análisis de las políticas públicas, una denuncia de la situación de la creación local, una acción simbólica y casi performática en la que se renuncia a la ayuda económica para cortar con la cadena de precarización y una petición frontal de unas políticas culturales que cuenten con figuras profesionales del sector con capacidad real de decisión. Todos estos puntos que aparecen a lo largo de su trayectoria artística están presentes en los 4 folios de la carta. Es ahora cuando podemos entender que una catalogación habitual de un fondo de museo caería en el riesgo de perderse toda la potencia política que subyace del propio gesto y la verdadera memoria del archivo, condenada a desactivarse. 
En el año 1999 la organización sin ánimo de lucro Rhizome, fundada en el año 1996 por el comisario y artista Mark Tribe, desarrolló un proyecto aún vigente bautizado como ArtBase. Un archivo en línea que se concibió como una base de datos que aglutinara trabajos artísticos desarrollados en red. Poco a poco se fueron incluyendo otro tipo de perfiles como softwares, juegos o incluso la conservación piezas que fueron realizadas con un código obsoleto a día de hoy. En el año 2011, el conservador del archivo, Ben Fino-Radin publicó un informe titulado "Digital Preservation Practices And The Rhizome rtbase" (Fino-Radin, 2011). El documento advierte de varios retos a los que el arte realizado en soporte digital se enfrenta en la actualidad. Desde aquellas piezas que dependen de la interacción de bases de datos online que han dejado de existir a trabajos que se nutren de otros contenidos en la red. Si bien, por las características de ArtBase no profundiza en esta cuestión, si se refiere a la obsolescencia física como un problema a tener en cuenta, así como a la imposibilidad de leer almacenamientos de datos que se convertirán en un objeto sin ningún uso posible.

Muchas de las obras de Fundación Rodríguez corren ese riesgo. Sistemas de almacenamiento de archivo, contenido digital organizado con una perspectiva comisarial y de investigación que pueden quedar cojo pues el contenido deja de ser visible o accesible. Una página web que es tan relevante como un objeto artístico o un DVD que es a la vez una compilación de textos, vídeos y documentación. Esto es, enfrentarnos a la desmaterialización y promover una suerte de "rematerialización". Volver a convertir todo aquello que quedaba conservado en un fino disco brillante, en un nuevo cuerpo que nos permita acceder al contenido. Este puede concebirse como una estrategia de investigación que utilizando los códigos del arte (exposición, publicación) aleje el archivo del peligro de la obsolescencia. Contra esto, quedan dos opciones: Crear un espacio recopilatorio de toda la memoria, reubicando blogs, archivos, contenido e imágenes, como si de una migración de datos se tratara y por último asumir todo este legado para que pueda ser leído e interpretado desde el presente, reivindicando la posición de Fundación Rodríguez en el contexto al que pertenece. El archivo, para que tenga sentido, debe poder ser consultado, absorbido, reinterpretado y asumido.

\section{Análisis de la producción “Rodriguista"}

El desarrollo del primer punto nos ha permitido conocer el objeto de la investigación, así como la metodología aplicada para la realización de la misma. Fundación Rodríguez como un colectivo que ejerció desde la práctica artística una labor de disolución en el ámbito del arte activando diferentes estrategias de producción formatos, obras y dispositivos. En donde la reflexión en torno al archivo y a la presencia de "lo archivado" se desvela ahora con la distancia que permite una relectura de su legado desde un análisis completo del contexto. A su vez, el propio archivo cedido en depósito en el Centro Museo de Arte Vasco ARTIUM, que nos obliga a desarrollar una investigación a medio camino entre la catalogación y la construcción de un relato que permita atinar con cada uno de los puntos que conforman su carrera. Ambas partes están presentes en este artículo de manera paralela, siendo una inseparable de la otra y en ocasiones llegando a puntos de contacto.

En este segundo punto, analizaremos una selección de los proyectos de Fundación Rodríguez que consiguen representar las líneas de trabajo acometidas por el colectivo y que nos permitirán entender las diferentes maneras de relación con la práctica artística que planteábamos al inicio del artículo. Es en este momento cuando conviene recordar los tres vértices entre los que situábamos la producción rodriguista y que atravesarán todo el análisis. El colectivo como 
punto de partida, metodología y forma de relacionarse con su entorno profesional y político. Una reivindicación del hacer con otrxs y desde lo compartido que los liga directamente con la herencia recibida de los movimientos sociales y los proyectos autogestionados y no tanto con los precedentes de colectivos artísticos en Euskal Herria. Esto trae consigo una práctica muy ligada al do it yourself y a la cultura libre. De ahí que la disolución de roles a la que nos hemos referido en el primer punto sea una de las cuestiones que marcarán su práctica. Las barreras entre las figuras de artista, críticos, comisarios, investigadores, se difuminan con un barrido para sedimentarse de nuevo como una multitarea basada en la conjunción entre el pensamiento y la creación. En consecuencia, los modos de creación y distribución de su trabajo, se asentará en un terreno atravesado por la desmaterialización del objeto artístico, formatos accesibles y abiertos, así como la creación de redes de relación como una expansión de la práctica colectiva.

El archivo aparece entonces en varios de sus trabajos, desde diferentes perfiles. Las páginas web, blogs o DVDs son portadores de proyectos planteados desde el espacio digital y en consecuencia, y leídos desde el ahora, de un archivo casi repositorio que recoge experiencias de corte comisarial que indaga en las posibilidades de lo digital, como "Intervenciones TV" (1998), "Arte y Electricidad" (2001), "Tester" (2002) o "Web-Side" (2003). Por otro lado, la labor artística del colectivo que ya desde su etapa en S.E.A.C se vinculó en muchas ocasiones a la práctica performática en la que sin embargo la desmaterialización de los proyectos está presente desde un tono casi humorístico como en "Que se mueva la colección" (2011) y "T-Shirt" (1994-2012). Por último, y desarrollando una labor más cercana a la investigación, proyectos como "[En torno a] En torno al vídeo" que realiza una revisión de una publicación de 1980 y su relectura actual. En las siguientes líneas profundizaremos entonces en todos estos títulos con la intención de generar una visión panorámica de estos hitos que estructuran gran parte de su recorrido, permitiéndonos así atravesar su legado desde los ejes planteados en el primer apartado del artículo. Si bien dividiremos el análisis en tres grandes grupos existirán muchos puntos en común que será inevitable no pensarlos por separado. Aunque evitaremos la cuestión cronológica veremos los hilos que los conectan entre sí. La investigación requiere de clasificación de contenido, pero eso no quiere decir que esta sea la única manera de entenderlo. Muchos proyectos de la Fundación se solapan entre sí y están relacionados temporal y conceptualmente y es esta no diferenciación la que caracteriza su genética.

En este tiempo, la no diferenciación entre reflexión teórica y práctica artística (ya que somos ajenos a la diferencia entre pensamiento y acción), nos ha situado ante un panorama necesitado de nuevas fórmulas de comisariado y de producción, así como de nuevos modos para la difusión y la distribución del hecho artístico actual. Nuestro trabajo se ha afianzado con el tiempo en conceptos como la disolución de los formatos y la emisión libre del conocimiento. (Fundación Rodríguez, 2011)

\subsection{Archivo digital. Repensar el soporte}

En el año 1998 Fundación Rodríguez asumió la gestión del Festival de Video de Vitoria-Gasteiz durante cuatro ediciones hasta el año 2001. De nuevo, su rol como colectivo artístico se transforma para acercarse a la gestión y comisariado de un proyecto de contrastada trayectoria en la ciudad (de hecho 1998 era la edición número XIII). Más tarde el festival evolucionó en "VTV, Vitoria territorio visual" que actuará como un paraguas para diferentes iniciativas en torno a las artes visuales. 
En el año 1999, Fundación Rodríguez propone que el festival no sea solo un espacio de muestra, sino que pueda convertirse en un contexto para producción. La desaparición del CINT (Centro de Imagen y Nuevas Tecnologías, con el que tenían relación) permite contar con una serie de recursos para la creación de contenido que luego sería emitido en la televisión local. De esta propuesta nace "Intervenciones TV", con un formato que toma cuerpo y que pone la televisión en el centro como una reflexión en torno a la producción artística y los mass media (todo esto antes de la aparición de plataformas de streaming, youtube o la llegada de los smartphones).

El proyecto fue evolucionando y sumando más capas de desarrollo. Desde eventos públicos y de carácter más lúdico como "TV JAM" a las jornadas "Televisores: Encuentros sobre TV alternativa" en el Centro Cultural Montehermoso que contarían con invitados como Fran Ilich o Zemos 98. Entre el elenco de nombres que tomaron parte en las diferentes ediciones encontramos nombres como Jon Mikel Euba, Itziar Okariz, Ibon Aranberri, Idoia Zabaleta, Mabi Revuelta o Eugeni Bonet, Antoni Muntadas y Left Hand Rotation.

Tras diez años de gestión y once ediciones, Intervenciones TV genera una gran cantidad de contenido que a día de hoy puede visitarse en internet. ${ }^{3}$ Materiales cuya resolución aparece mermada por la calidad actual de las pantallas pero que permanece disponible. Un archivo online que nos permite reflexionar sobre el papel de la producción artística, su relación con los nuevos medios y la ocupación de espacios de difusión que superan el ámbito de lo expositivo hasta la conquista de la cotidianeidad mediante la televisión local. Este cuestionamiento de las barreras de los formatos no solo se da entonces en el soporte digital en el que ahora se encuentra el archivo, sino que incide en las diferentes potencialidades del audiovisual como una herramienta central a día de hoy en una cultura visual que condiciona nuestras miradas y la multiplicidad de pantallas.

Siguiendo esta estela "Arte y electricidad" (en adelante A\&E) es uno de los proyectos más conocidos del colectivo. Puesto en marcha en el año 2000 y con la colaboración de Arteleku en la producción, aún cuenta con una página web propia ${ }^{4}$ que, aunque requiere tecnología flash para ser ejecutada, nos permite navegar por su contenido. Volvemos de nuevo a la desmaterialización de la obra y a la hibridación de formatos como estructura principal de la identidad del proyecto.

A\&E no es: una exposición, un CD-ROM, un proyecto temático, comisariado, tutorizado una iniciativa de promoción de arte joven. A\&E es: un experimento colectivo, una propuesta multiforme y en proceso, una apuesta por descubrir nuevas vías, un modo de trabajar que ha comenzado en el año 2000...A\&E puede ser una sesión de música, o de vídeo, o de vídeomúsica, puede ser un debate y/o un debate en la red. Pueden ser nuevas situaciones pensadas para acontecer en la red. Puede ser el visionado personalizado en pantalla o la proyección pública de una serie de propuestas audiovisuales. Puede ser también una serie de juegos. A\&E puede ser todas estas cosas en forma de fiesta de presentación, o todas y cada una de ellas explicando las demás en una amable charla (Fundación Rodríguez, 2000).

La tecnología es el punto de partida, pero no el objetivo. No estamos ante una reflexión sobre el propio medio sino sobre las posibilidades del mismo para la creación de la práctica artística. En este sentido, entenderemos este concepto de una manera especialmente amplia, pues A\&E propone un formato que es a la vez proyecto, distribución y pieza. Una publicación compuesta por dos CD-Rom y una página web, son los dispositivos que han trascendido al paso del tiempo. El contenido de dichos $C D$, es una serie de trabajos artísticos llevados a cabo por un total de 20 
autores/as en los que se mezclan el vídeo, el audio, el net.art o las propuestas interactivas. La parte interna del CD advierte: "una propuesta multiforme empaquetada en varios formatos: vídeo, web, cd o fiesta de la cual aquí tienes una de sus formas posibles". Por otro lado, una página web en la que Jorge Luis Marzo y Javier San Martín fueron invitados para la realización de unas contribuciones a modo de una suerte de hipertextos organizados a través de hipervínculos, además del contenido de los trabajos que también aparecen en la publicación.

La Fundación Rodríguez incide en lo que ellos llaman "la segunda etapa del do It Yourself", cuando recupera el pensamiento Punk y de la cultura popular en cuanto a los formatos de autogestión y formas de autoproducción cultural. Autores como José Luis Brea (2009) o Guattari y Rolnik (2005), hablaron de la era postmedia como la superación de la cultura massmediatica por parte de los colectivos empoderados a través de las posibilidades de los nuevos medios. Este nuevo terreno que propiciaba la proliferación de internet y la nueva disposición de los medios tecnológicos para la creación y distribución atraviesa todo el proyecto A\&E para erigirse en sí mismo como un cuestionamiento.

El propio formato en sí es una cuestión sobre su existencia negando cada parte de su evidencia. Es un $C D$ que niega su condición de $C D$, una publicación que supera los límites de la publicación, un programa de vídeo que se expande fuera del formato vídeo y por supuesto un postulado teórico que se difumina entre las cuestiones planteadas por cada uno de los trabajos.

Cabe destacar que a pesar de la fecha de realización (2000-2001), no es un proyecto ciberutopista que proponga el medio digital como única herramienta liberadora para las prácticas artísticas desjerarquizadas. Hay una cuestión de fondo que es la búsqueda de posibilidades, de terrenos nuevos y sobre todo de creación de red. Prueba de su expansión es que fue presentado como su presencia en la exposición comisariada por Jorge Luis Marzo "En el lado de la televisión" bajo el nombre A\&E TV, festivales como Música Ex-Machina o como proyecto ganador del X festival de Creación Audiovisual de Navarra, obteniendo una mención especial en la categoría de "CD/ Internet".

Uno de los puntos destacables del proyecto es cómo a pesar de materializarse de diversas maneras, tanto públicas como virtuales, el CD-Rom fue distribuido dentro del número de julio y agosto de la revista NEO2 de tirada nacional e internacional. Las formas de distribución desafían una vez más a los canales habituales del arte contemporáneo y asumen un rol cercano al fanzine que circula de mano en mano, o a la revista.

A\&E es uno de los hitos más importantes de Fundación Rodríguez y un proyecto de una riqueza inapelable. La cantidad de matices, campos de estudio y puntos de interés que abre en relación a su propio contexto siguen aún hoy vigentes. La carrera de la digitalización no ha terminado y las condiciones de producción de contenido con la irrupción de internet, vivieron una segunda etapa evolutiva con la entrada de plataformas de difusión de vídeo, la accesibilidad a internet y las redes sociales. Un paradigma aún en desarrollo que sin duda ha removido los cimientos de todo aquello que parecía establecerse hasta mediados de los años 2000. Las maneras de relación han cambiado igual que ha cambiado la forma de entender, comunicar y contar lo que sucede. Las preguntas de A\&E siguen siendo válidas casi 20 años después.

Entre 2002 y 2005 el proyecto "TESTER" recogerá varios de los aprendizajes extraídos de A\&E para orientarlos hacia unos postulados semejantes, pero además hacia una reflexión sobre 
las maneras de colectividad y de organización horizontal que pudieron darse alrededor del proyecto. "TESTER" vuelve a ser una página web aún accesible ${ }^{5}$, una publicación en formato DVD, actividades en el espacio físico (presentaciones, conferencias, fiesta) e incluso un libro publicado y disponible en formato PDF.

\section{Nuestro intento en la forma de poner en marcha TESTER, quiere atender especialmente a los modos y las condiciones en que se realiza la producción, buscando alternativas y proponiendo nuevos modelos de relación y mediación siempre acordes con las nuevas situaciones contextuales, con los nuevos soportes y los nuevos sistemas de producción de subjetividad. (Fundación Rodríguez, 2002-2005).}

"TESTER" se centrará en la idea de periferia y descentralización de las prácticas artísticas. Atomizar el proyecto y disolver la autoría de la Fundación será lo que consigan mediante una organización a base de "nodos". "TESTER" se desarrolló de forma paralela en diferentes contextos internacionales llegando así a crear un proyecto que estaba a la vez tremendamente arraigado a la realidad local tal y como se puede leer en la cita anterior, pero que se expandía hacia la internacionalización. Este mirar hacia fuera no respondía a una pretensión de vanidad o visibilidad si no a una apuesta por la colaboración entre contextos y la búsqueda de lugares comunes en donde trascender hacia una organización marcadamente política. Cada "nodo" actúa como comisario en su propio país, aportando una serie de autores, piezas y contenido teórico que constituye el proyecto final.

Los nodos son los siguientes:

Fundación Rodríguez (Euskal Herria), Marina Grzinic (Ljubljana, Eslovenia), José Carlos Mariategui (Lima, Perú), Hito Steyerl (Berlín, Alemania), Marcus Neustetter (Johannesburg, Sudáfrica) y Oliver Ressler (Viena, Austria) y estos a su vez hacen extensivo el proyecto hacia el listado de autores y autoras y las consiguientes actividades y encuentros que esto pueda suscitar.

Tester es por tanto un proyecto de investigación, una experimentación comisarial, una publicación, una red internacional, un DVD de videoarte, un póster con un mapa, una fiesta, una reflexión, una página web, un texto interactivo, una pegatina que anuncia una publicación a $5 €$, una charla o un acto performático. Abarca múltiples formas de ser y toma cuerpos diferentes. Expande su forma de materializarse y de distribuirse.

La vigencia de este proyecto es indiscutible. Del propio análisis subyace una reflexión sobre la manera de relación que tiene que ver con una puesta en duda de la fisicidad de los cuerpos. La desaparición de la presencia y la interconexión de los relatos a través de lo digital. La posibilidad de encontrar afinidades a partir de la búsqueda de espacios comunes en las que diferentes narrativas se hacen posible. La carne no desaparece, la piel está en cada paso, pero hablamos de una serie de identidades que el arte parece anticipar a un presente en el que nos encontramos actualmente, que experimenta un nuevo paradigma de la capacidad de la imagen para su creación y reproducción. El DVD como formato de exhibición artística, incluyendo dentro comisariados y trabajos colaborativos de 6 países diferentes, es sin duda un acto revolucionario que sigue desafiando las maneras actuales de abordar la creación. 


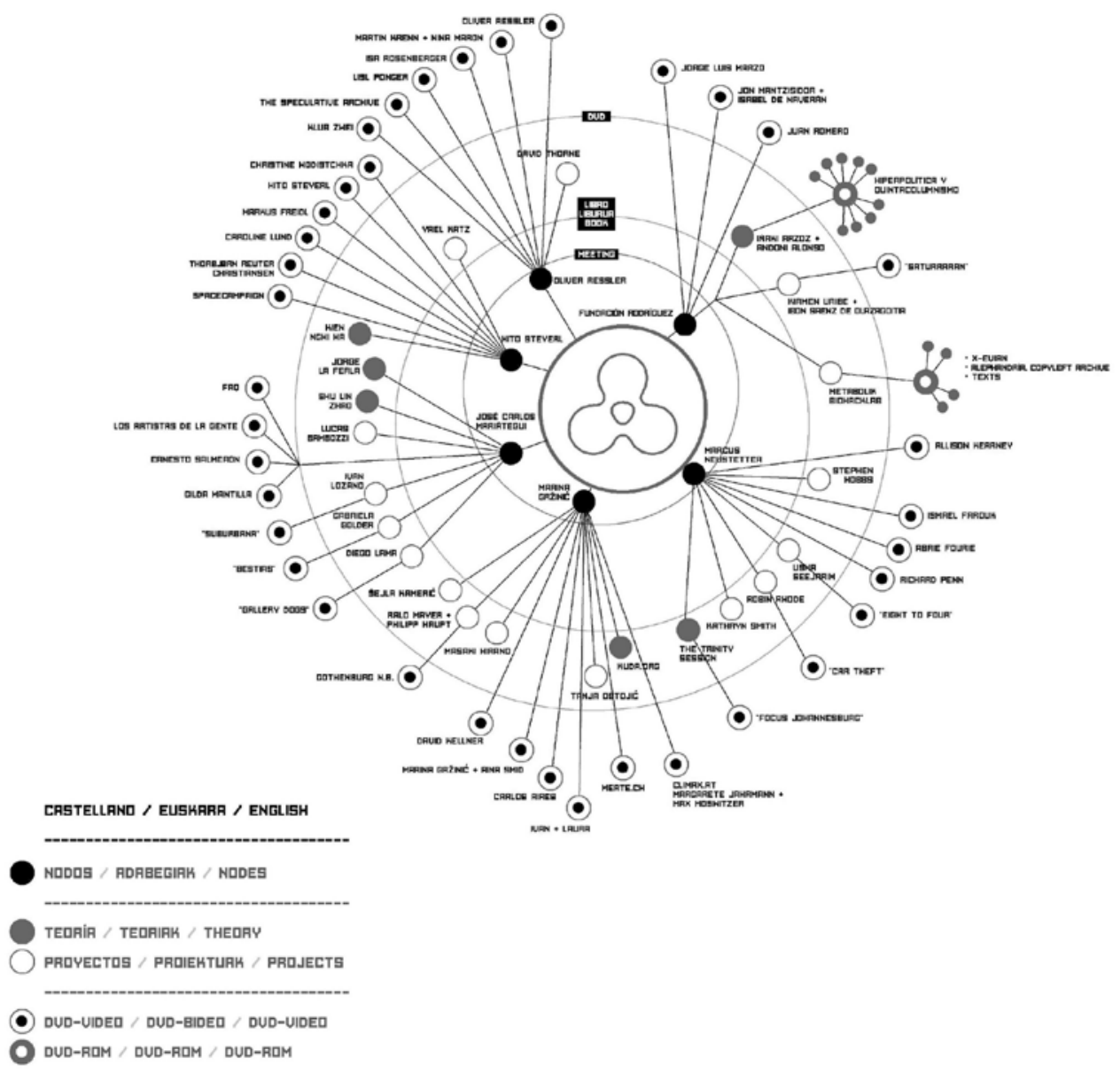

Figura 1. Archivo Fundación Rodríguez. Esquema de nodos del proyecto "TESTER". 2002-2005.

El final de este primer bloque en el que hemos analizado diversas propuestas en las que el archivo digital es repensado desde las potencialidades que nos ofrece, debemos destacar el proyecto "Web-Side". Si bien el punto de partida es totalmente diferente pues hablamos de un trabajo encargado por una institución, encontramos líneas metodológicas que tienen que ver con la reflexión sobre la cultura digital, el auge del multimedia y las nuevas capacidades de aprendizaje que se desarrollan al respecto.

La Mediateca de la Fundación La Caixa, pone en marcha un proyecto de web que bajo el título "Web-side" se erige como un espacio para la investigación teórica en torno a la cultura digital en su espectro más amplio, periodismo, investigación, filosofía, crítica, etc. La Fundación Rodríguez será la encargada de la puesta en marcha de la segunda edición que bajo el título "Mapas para la desorientación" lanzan una convocatoria en el año 2003 para la recepción de proyectos de 
los que resultarán elegidos casi 30 y en donde encontramos nombres como Remedios Zafra. El propio cometido de la convocatoria denota una investigación previa sobre unos ejes temáticos que comienzan a ser lugares comunes en muchos de los proyectos.

En una reflexión sobre el devenir de la sociedad de la información (recordemos, aún momento pre youtube y pre RRSS tal y como las concebimos ahora), la Fundación ya advierte de una serie de cuestiones que tienen que ver con el control de nuestras relaciones y de todo aquello que supone:

¿Cómo combatir desde el propio cibermundo la desorientación inducida en las políticas de las grandes corporaciones y desde los gobiernos? ¿De qué modo cabe plantearse un trabajo "incrustado en el sistema" que propicie espacios para la libertad y la crítica del propio sistema? ¿Cómo incrementar los medios que fortalezcan una ciudadanía global bien informada y comunicada sin poner en peligro la diversidad cultural? (Fundación Rodríguez y Zemos 98, 2007, p.17).

\subsection{Archivo físico. Evocar la experiencia (la memoria)}

En varias ocasiones hemos advertido cómo Fundación Rodríguez desarrolló su propuesta artística en diferentes ámbitos, creando una práctica difuminada que disolvía las fronteras entre disciplinas y espacios de trabajo. Esto puede entenderse como una práctica política desde la que cuestionar espacios de poder que dentro del esquema del arte puedan llegar a darse. La gestión, el comisariado, la postulación teórica, la performance o la escritura crítica son entendidos como un todo. No se trata de una necesidad de acaparar todas las áreas, sino más bien de una manera de conquista de ciertas estructuras que permita espacios comunes para el trabajo colectivo y una llamada de atención a los espacios de decisión de la gestión pública.

Con todo, existen trabajos cuya aproximación metodológica está muy cerca del ámbito de lo performático y la intervención artística. Ya desde los tiempos de S.E.A.C en cuyo archivo se encuentran acciones como la visita de los cuatro miembros del colectivo ataviados como futbolistas de la Selección de Euskadi de fútbol, a las obras de un incipiente Museo Guggenheim de Bilbao en el año 1994. La visita sorpresa fue recibida por el actual director ejecutivo del Museo, Juan Ignacio Vidarte, que accedió a explicar el proyecto a aquellos cuatro jóvenes que se presentaron como Selección de Euskadi de Arte de Concepto. Finalmente, en la aparentemente inofensiva visita, se sucedieron por parte de los protagonistas, varias preguntas y observaciones sobre ordenación urbanística y desarrollo cultural, denotando un conocimiento de las estructuras a las que se referían. Un acto no exento de humor que en el fondo ridiculiza la utilización de símbolos (selección nacional, Museo, ...) para la legitimación de la práctica y que se presenta como una interferencia en el curso habitual de los acontecimientos.

En el año 2011, el Centro Museo Vasco de Arte Contemporáneo Artium de Vitoria, anunció un proyecto comisariado por Mar Villaespesa y BNV producciones: "Estancias. Prácticas reconstituyentes sobre la colección Artium". El objetivo del mismo era reactivar diferentes piezas de la colección a través de una interlocución con diferentes protagonistas que se acercarían a las piezas desde un formato de estancia. La primera corrió a cargo de Valentí Roma bajo el título "La verdad radica en el extremo". La segunda fue la de Fundación Rodríguez y fue bautizada como "Algunas acciones para CMVAC". El colectivo Bulegoa z/b fue el tercer agente invitado 
con "una, dos, tres, cuatro paredes" mientras que "Fuera de control: laboratorio de imágenes obliteradas" supuso la última de las estancias a cargo de Laura Trafí-Prats. Un planteamiento del propio centro que provocaba la necesidad de sumergirse en su propia estructura para ser reinterpretada y reactivada por parte de cada uno de los agentes invitados.

Fundación Rodríguez durante su turno, profundizará en el concepto de "acción" para la labor que van a desempeñar. La relación con la colección del museo abarcará una cuestión mucho mayor que tiene que ver con la condición del museo como estructura, cultural y arquitectónica.

Una de las acciones planteadas se titulaba "Que se mueva la colección". Esta proponía exhibir por primera vez las 3.087 piezas que conformaban la colección del centro. La manera de hacerlo no era otra que imprimir y colocar en un gran mosaico las fichas de catalogación en las que aparece una fotografía, así como información relativa a sus medidas y materiales. Una vez colocadas de tal manera que pudieran ser afectadas por una corriente de aire, se propuso una fuente de ventilación que creaba un movimiento pausado, como una onda que mecía el mosaico de papeles, casi como un oleaje.

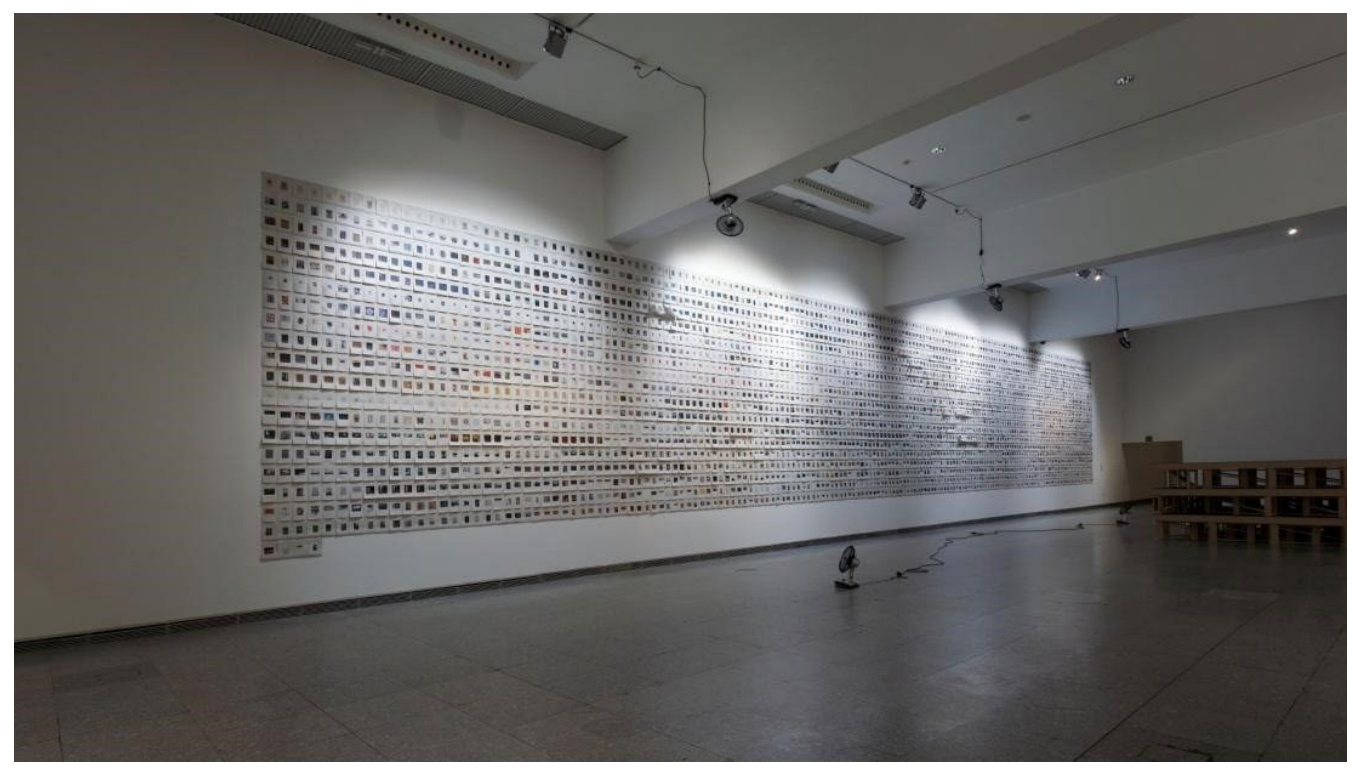

Figura 2. Archivo Fundación Rodríguez. "Que se mueva la colección”. Vitoria-Gasteiz, ARTIUM. 2013.

En esta acción hay un doble juego. Por un lado, la visualización de la documentación de todo aquello que el museo, como contenedor de tesoros ocultos, conserva en las catacumbas de su estructura, de la que solo vemos las piezas que nos son presentadas en cada nueva exposición. Por otro, la reducción de la obra de arte a documento, a ficha. Mientras todo lo que supone una pieza artística queda embalado y protegido contra la humedad y los ácaros, la pieza vive solo como dossier catalogado, como una ficha más de un archivo. Fundación Rodríguez pone eso encima de la mesa, muestra la obra como documentación y la documentación como la única obra posible y manejable dentro de la infraestructura expositiva. Por último, esta visión general de todos los fondos, nos llevan a un relato del fondo público como bien común. Una serie de elementos que no son de nadie, pero pertenecen a su vez a toda la ciudadanía. 
La conservación como la misión encomendada y la máxima expresión de la obra de arte que se representa simbólicamente en un objeto que necesita ser cuidado para las generaciones futuras como un elemento que lucha contra el paso del tiempo, el desgaste o el accidente. Ese legado del arte contemporáneo compuesto de grandes almacenes que acumulan objetos embalados cuya función como obra desaparece para convertirse en bulto, se inscribe en las lógicas artísticas que Fundación Rodríguez cuestiona en la mayoría de sus trabajos.

En este marco que tiene que ver con la gestión del rastro de la obra artística y su vigencia a lo largo del tiempo. Fundación Rodríguez inició ya en los tiempos de S.E.A.C una acción que acabó por conformar una especie de visión retrospectiva de toda su carrera. El acto efímero como centro de su trabajo reivindicado desde los tiempos de la Selección y la idea de la desmaterialización de la pieza junto con un origen ligado a la cultura popular y los movimientos sociales autogesionados son los ingredientes desde los que poco a poco se conforma la colección que engrosa "T-Shirt". Algo tan sencillo como la creación de camisetas conmemorativas de cada uno de sus proyectos que los acerca a las maneras de una banda de rock y al merchandising de furgoneta y carretera. La cuestión es que las camisetas no son únicamente un recordatorio, sino que en muchas ocasiones son el único rastro físico del proyecto y esto vuelve de nuevo a dirigir su potencia contra la propia conformación de la obra artística. Las camisetas de algodón $100 \%$, serigrafiadas, se encuentran ahora mismo almacenadas en el archivo en depósito que custodia el museo vitoriano. Algo tan accesible, barato y popular como una camiseta negra con un logotipo es a la vez una obra de arte cuyas copias duermen ahora años después en el cajón de los pijamas de amigos y gente cercana a la Fundación que se hicieron con ellas en su momento. Mientras por un lado necesitan ser clasificadas o expuestas en una vitrina protegidas de un posible público, en otro están a punto de servir para trapos.

"T-Shirtografía" es el nombre de una performance en la que la Fundación ordena pegando sobre una pared, los diferentes proyectos que conforman su legado. Ambos artistas se visten con todas las camisetas que van quitándose una a una por orden hasta que todas aparecen colgadas con trozos de cinta. Un ejercicio en el que sobre una pared disponen lo más parecido a un archivo propio, una memoria habitada por sus cuerpos, por el gesto y por una trayectoria que es evocada desde la experiencia y no desde el objeto.
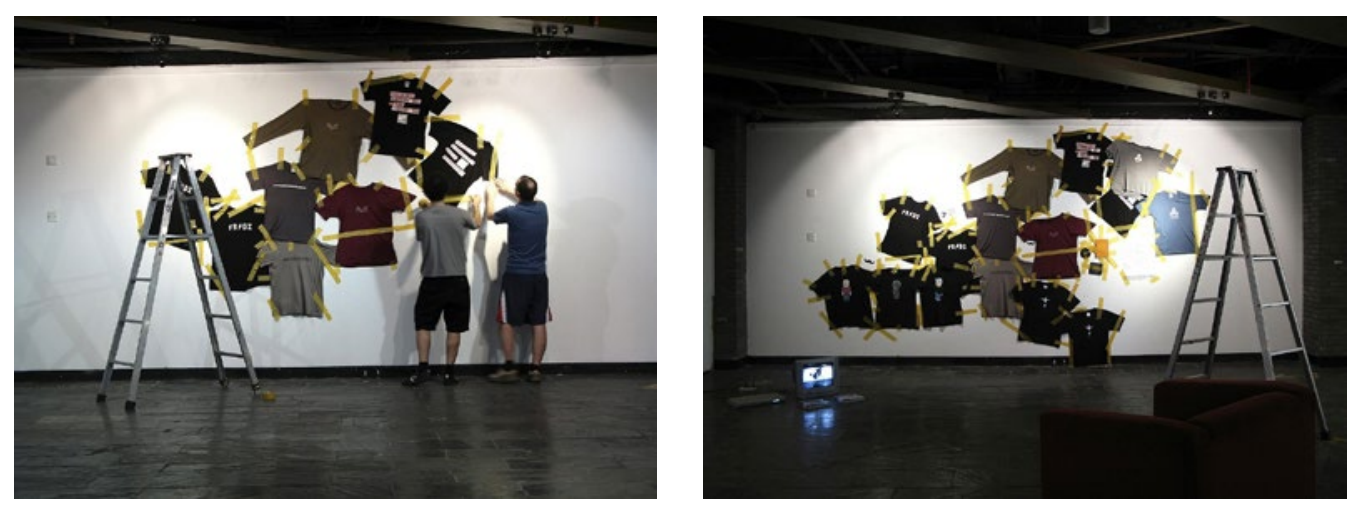

Figura 3 y 4. Archivo Fundación Rodríguez. Performance realizada en Shangai (China). 2007. 
En el año 1980, la editorial catalana Gustavo Gili publicó el volumen "En torno al vídeo" con la participación de Eugeni Bonet, Antoni Muntadas, Joaquím Dols y Antoni Mercader en lo que supone un elenco conformado por cuatro de las voces más autorizadas en el campo de la creación artística ligada al vídeo. Cuatro años antes, en 1976, los propios Bonet, Muntadas, Mercader y Dols realizaron unas sesiones de trabajo en el Institut del Teatre en colaboración con el Institut Alemany que dará lugar a una publicación titulada "Dossier: Video". Esto supuso el germen para la publicación de 1980 que acabará por convertirse en una de las referencias inapelables para acercarse a la disciplina vídeo y sus primeros planteamientos en el Estado.

En el año 2010, con motivo del 30 aniversario de la publicación, Fundación Rodríguez propone una revisión de la publicación como una lectura desde el presente de la creación videográfica. Si a lo largo de su trabajo, la cuestión tecnológica y las posibilidades que este campo posibilita a la creación artística están constantemente presentes, la reflexión sobre estos primeros postulados teóricos sobre la creación en vídeo, desde una época condicionada por el estallido del digital y la creación de internet subraya una línea de investigación muy relevante para el campo de la creación audiovisual.

Como parte de la última edición del proyecto Intervenciones TV, Fundación Rodríguez realizará un proyecto que se divide en tres fases diferenciadas. Por un lado, una reedición del volumen "En torno al vídeo" que contará con la colaboración de la UPV/EHU. Esto permitirá rescatar del mundo de la descatalogación editorial un texto que se considera clave en la historia del videoarte. Por otro lado, la publicación de "En torno a En torno al vídeo" en colaboración con el Centro Cultural Montehermoso, realizará un replanteamiento de aquellos textos mediante colaboraciones con distintos autores que actualizan aquellas primeras reflexiones 30 años después. En este interesante ejercicio, los cuatro autores del primer volumen son entrevistados por agentes culturales de gran relevancia. Antoni Mercader junto con Arantza Laurizika, Joaquim Dolls con Iñaki Arzoz, Eugeni Bonet con Itxaso Díaz y Antoni Muntadas junto a Zemos 98, darán lugar a cuatro conversaciones capaces de describir un contexto del que beben ambas temporalidades. En esta puesta en común generacional aparecerán cuestiones como el archivo, internet, la creación colectiva, el papel de la televisión o la cuestión tecnológica entre muchos otros. A estas entrevistas, se sumarán en una segunda parte, textos de Gabriel Villota, Juan Guardiola, Josu Rekalde, Virginia Villaplana y Maite Ninou.

Esta publicación complementaria, asume desde el principio una responsabilidad generacional como colectivo. Por un lado, recuperando y poniendo a disposición del contexto actual un material cada vez más difícil de conseguir, con todo lo que eso supone a nivel de negociación institucional, búsqueda de financiación etc. Por otro, desde su propia práctica artística, una relectura propiciada por artistas actuales capaces de problematizar desde diferentes puntos de vista para el enriquecimiento de aquella propuesta. Desde el primer boceto en 1976 hasta este proyecto en el año 2010, el mundo de la imagen cambia tan radicalmente como nuestras maneras de consumirla y relacionarnos, con y a través de ella.

Ligado a este proyecto, y ya en el año 2011, Fundación Rodríguez será el colectivo comisarial que dará forma al programa "Era vídeo: Entornos y potencias (80-00)" en el Museo Nacional Centro de Arte Reina Sofía (MNCARS). Utilizando como punto de partida la reedición de "En torno al vídeo", proponen unas jornadas con la presencia de Iñaki Arzoz, Itxaso Díaz, Marcelo 
Expósito, Pedro Jiménez (Zemos 98), Arantza Lauzirika, Eli Lloveras (Hamaca), Antoni Mercader, Karin Ohlenschläger y Gabriel Villota. Cada una de las jornadas contaba con proyecciones de trabajos de diferente índole en relación con las temáticas tratadas en las sesiones. Las jornadas coincidieron casualmente con la gestación del 15M en Madrid, en lo que a la postre significaría una nueva etapa de la autogestión del relato a través de la producción videográfica.

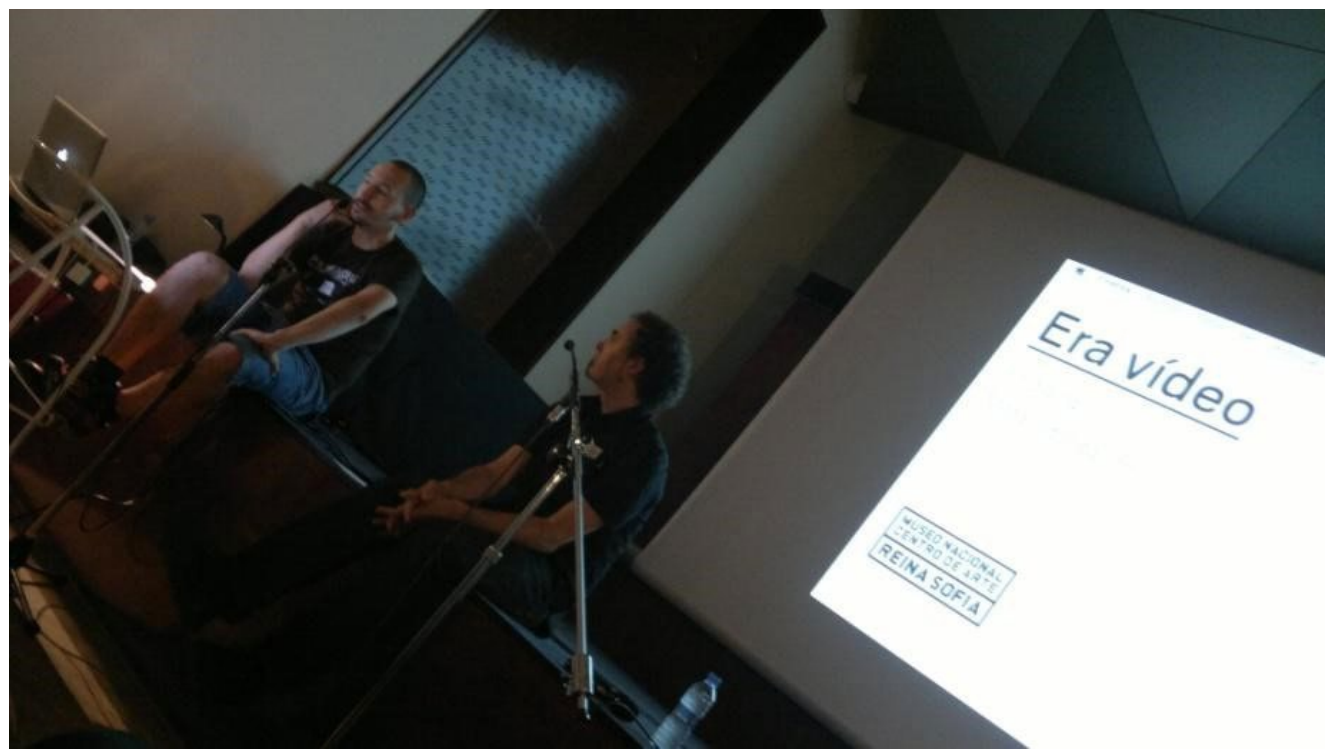

Figura 5. Archivo Fundación Rodríguez. Presentación jornadas MNCARS. Madrid. 2011

3 A modo de conclusiones: vivir el archivo

El artículo ha analizado desde el caso de estudio concreto de Fundación Rodríguez, la presencia del archivo en su práctica y a su vez el estado y gestión de su propio archivo depositado en los fondos de una institución pública. En el caso que nos ocupa, nos referimos además a una práctica artística basada en gran parte de su legado a la creación de estrategias artísticas entre lo performático, el activismo y la puesta en duda de los soportes, hábitos y maneras del arte contemporáneo. Su memoria es entonces tan ecléctica como su trayectoria y aquello que queda, su archivo, es en el fondo una conjunción de elementos tan dispares como una camiseta, un email, una carta o un vídeo.

El objeto de toda investigación es extraer conclusiones que puedan aportar una capa de experiencia a una comunidad científica o especialista. Es por eso que los casos de estudio en el fondo no son demostraciones de unos postulados concretos, sino que son análisis desde lo concreto. Por eso, si bien partimos de Fundación Rodríguez, de su práctica y de la gestión de su archivo, entre las líneas del artículo subyacen reflexiones sobre las maneras de conservar y sobre todo de poner en disposición pública aquello que se almacena como parte de una colección de un centro o museo. La misión de los museos no es (o no solo) es la conservación y salvaguarda sino la creación de estrategias y maneras para que aquello que se almacena encuentre sus propios espacios no solo de visibilidad sino de diálogo con diferentes discursos afines a su 
contemporaneidad. Esto que pudiera parecer fácil cuando nos referimos a un cuadro o una pieza escultórica pues forman ocasionalmente parte de exposiciones colectivas o préstamos a otros museos, se complica cuando el objeto en cuestión no es más objeto o es tan solo un breve retazo de algo que sucedió y para cuya lectura apenas existen herramientas tecnológicas.

Obviamente no existen respuestas claras para tales preguntas y una de las potencias del archivo de Fundación Rodríguez es precisamente la creación de ese conflicto. Un colectivo que años después de su disolución sigue, desde la aparente indefensión de un disco duro encerrado en un armario, cuestionando las lógicas de la institución artística denota una vigencia de aquellas prácticas.

Si bien, hemos ido atravesando todo el escrito desde la cuestión colectiva, la disolución del rol del artista y la producción desde la desmaterialización y los principios de la cultura libre, años después, no se trata de volcar exclusivamente en la figura concreta del museo de arte contemporáneo la tarea de activación del contenido. Existe una capa más allá, que es el comenzar a pensar como el sistema del arte contemporáneo será capaz de asumir toda la producción que el mundo digital nos ha traído y como la memoria pública (aquella que se custodia de las instituciones) será capaz de asumirla. O quizás pensar que el papel de esa memoria no deba ser tanto la mera conservación y si la creación de espacios para su puesta en valor como aprendizaje.

La práctica de Fundación Rodríguez puso en compromiso muchas de las cuestiones estructurales que vertebran el arte contemporáneo y supusieron un punto de partida que generaciones posteriores han asumido como propio. Su memoria no es solo una reivindicación nostálgica de aquello que sucedió, sino una propuesta actual sobre aquello que vendrá. Vivir su archivo será una manera de comenzar a asumir la responsabilidad que cada cual tenemos desde nuestro propio lugar. 


\section{REFERENCIAS}

Baigorri, L. y Cilleruelo, L. (2006). Net.Art (Prácticas estéticas y políticas en la red). Barcelona: Brumaria.

Brea, J. L. (2009). Retóricas de la resistencia: Una introducción (la potencia de los estudios críticos frente al triunfante "capitalismo antihegemónico"). Estudios visuales: Ensayo, teoría y crítica de la cultura visual y el arte contemporáneo, 7, 7-13.

Fundación Rodríguez y Zemos 98. (2007). Panel de Control. Interruptores críticos para una sociedad vigilada. Sevilla: Asoc. Cultural comenzemos empezemos (ZEMOS98).

Guattari, F. y Rolnik, S. (2005). Micropolítica: Cartografias do desejo. Petropolis: Vozes.

Marzo, J. (2016). La SEAC (Selección de Euskadi de Arte de Concepto): La difusa línea que separa al genio del carachorra. Vitoria-Gasteiz: ARTIUM. [Manuscrito no publicado]

San Martín, F. J. (2016). SEAC bien. Ensayo de aproximación al legado de la Selección de Euskadi de Arte de Concepto. VitoriaGasteiz: ARTIUM. [Manuscrito no publicado]

Steyerl, H. (2014). Los condenados de la pantalla. Buenos Aires: Caja Negra Editora.

Villota, G. (1997). Una PICCA en la SEAC. Zehar: revista de Arteleku-ko aldizkaria, no 33, 39-43. San Sebastián: Arteleku.

Virilio, P. (1997). El cibermundo, la política de lo peor: entrevista con Philippe Petit. Madrid: Cátedra. 


\subsection{FUENTES}

Fino-Radin, B. (2011). DIGITAL PRESERVATION PRACTICES

AND THE RHIZOME ARTBASE. New York: Rhizome ArtBase.

Recuperado de http://media.rhizome.org/blog/8332/rhizome-

digital-preservation-practices.pdf

Fundación Rodríguez (2000). Aye(es, no es). Vitoria-Gasteiz:

Archivo Fundación Rodríguez - ARTIUM. [Manuscrito no publicado].

Fundación Rodríguez (2002-2005). TESTER •¿QUÉ ES TESTER?

F.A.Q. - ¿Cuál es el tema de Tester?. Vitoria-Gasteiz. Recuperado

de: http://e-tester.fundacionrdz.com/cast/tester/faqs.html

Fundación Rodríguez (2011). 13 acciones para CMVAC -

AGEZMrako 13 ekintza. Vitoria-Gasteiz: Archivo Fundación

Rodríguez - ARTIUM. [Manuscrito no publicado].

Fundación Rodríguez. (s.f). Manifiesto Rodríguez. VitoriaGasteiz: Fundación Rodríguez. Recuperado de http://rdzfundazioa.fundacionrdz.com/fundacionrdz/castellano/textos/ fundacion/000056.htm

Gobierno Vasco, Dpto. de Cultura. (2004). Plan Vasco de la Cultura. Recuperado de http://www.euskara.euskadi.eus/ contenidos/informacion/argitalpenak/es_6092/adjuntos/plan_ vasco_cultura_c.pdf

\section{NOTAS}

1. https://www.araba.eus/botha/Boletines/2017/085/2017_085_02848_C.pdf

2. https://www.araba.eus/botha/Boletines/2018/072/2018_072_02363_C.pdf

3. http://intervenciones.fundacionrdz.com Consultado el 26 de septiembre de 2020.

4. http://arteyelectricidad.fundacionrdz.com/espanol/index.htm Consultado el 26 de septiembre de 2020.

5. http://e-tester.fundacionrdz.com/cast/index.html Consultado el 26 de septiembre de 2020. 